\title{
Depressed fathers' speech to their 3-month-old infants: a study of cognitive and mentalizing features in paternal speech
}

\author{
V. Sethna ${ }^{1 *}$, L. Murray ${ }^{2}$ and P. G. Ramchandani ${ }^{1}$ \\ ${ }^{1}$ Department of Psychiatry, University of Oxford, Oxford, UK \\ ${ }^{2}$ Winnicott Research Unit, School of Psychology, University of Reading, Reading, UK
}

Background. Depression in fathers in the postnatal period is associated with an increased risk of child behaviour problems. A key potential pathway of risk transmission is exposure of the child to negative cognitions and affect in the context of early parenting. This study examines paternal speech during face-to-face father-infant interactions at 3 months.

Method. Currently depressed $(n=19)$ and non-depressed $(n=19)$ fathers were individually matched on age and education. Speech was coded for cognitive biases and mentalizing statements using a modified version of previous measures of maternal speech. Paternal depression was diagnosed using a structured psychiatric interview.

Results. Depression in fathers was associated with more speech focused on the paternal experience and less on the infants' experience. Depressed fathers' speech comprised more negative and critical utterances, compared with nondepressed fathers.

Conclusions. Important differences emerge in the speech of fathers who experience depression. Examining negative cognitions in the speech of these fathers as early as 3 months may help in understanding children's risk in relation to paternal psychopathology.

Received 7 June 2011; Revised 9 February 2012; Accepted 18 February 2012; First published online 13 April 2012

Key words: Cognitive biases, depressed fathers, father-infant interaction, father's speech, mentalization.

\section{Introduction}

Evidence suggests that approximately $5-10 \%$ of fathers experience depression in the postnatal period (Paulson \& Bazemore, 2010). The disorder is associated with both parenting difficulties (Wilson \& Durbin, 2010; Davis et al. 2011) and an increased risk of behavioural disturbance and impaired cognitive development in the offspring (Ramchandani et al. 2008; Paulson et al. 2009). A range of potential mechanisms that may mediate the association between the occurrence of depression in fathers and adverse infant outcomes have been suggested (Ramchandani \& Psychogiou, 2009); however, empirical evidence is relatively lacking (Low \& Stocker, 2005; Kane \& Garber, 2009).

Depressive symptoms have a marked influence on social relationships, and this extends to the

\footnotetext{
* Address for correspondence: V. Sethna, D.Phil., Department of Forensic \& Neurodevelopmental Science, Institute of Psychiatry P023, King's College London, De Crespigny Park, London SE5 8AF, London.

(Email : vaheshta.sethna@kcl.ac.uk)
}

relationship that the parent establishes with their infant. One key pathway by which paternal depression may lead to adverse child outcome is through its effect on father-infant interactions. This is likely to include parental speech, which directly taps into a potential pathway involving negative cognitions and affect between a depressed parent and child. Parental speech contributes to the child's language acquisition, attributional style and emotional and cognitive development (Abkarian et al. 2003; Pancsofar \& VernonFeagans, 2006). Analysis of parental speech to the infant during face-to-face interactions in the early postnatal months may be particularly relevant to identifying aspects of interactive behaviour influenced by depression.

Two key features of early father-infant interactions are, first, cognitive biases (Beck, 1976), comprising the attentional focus and affect of the father's speech, and second, parental mentalization, the process of treating the child as a psychological agent, described variously in the constructs of attribution of agency (Murray et al. 1993), reflective function (RF; Fonagy \& Target, 2005) and maternal mind-mindedness (MMM; Meins

The online version of this article is published within an Open Access environment subject to the conditions of the Creative Commons Attribution-NonCommercial-ShareAlike licence <http://creativecommons.org/licenses/by-nc-sa/2.5/ $>$. The written permission of Cambridge University Press must be obtained for commercial re-use. 
et al. 2001). These three constructs share the core component of recognizing and interpreting mental processes, reflected in 'a meeting of minds' between parent and child (for a review, see Sharp \& Fonagy, 2008, p. 748). In the interest of conciseness, in this paper we use the term mentalizing to describe this attribution of mental states to the infant by the father.

To date, no published evidence exists on the impact of depression on cognitive biases and mentalization in the speech patterns of fathers. The few previous studies on paternal speech have largely examined syntactic and lexical features in parental speech registers to pre-verbal infants (Papousek et al. 1987; Fernald et al. 1989; Kaplan et al. 2007). Given the paucity of research concerning speech in fathers of depressed infants, we have drawn substantially on previous work with mothers. This includes the adaptation and use of scales previously used with mothers of infants, and the findings from maternal studies considered in the paragraphs that follow. It is important to note, however, that critical differences may exist between the speech used by mothers and fathers. In work on the wider aspects of parent-infant interactions, some differences are apparent. For example, fatherinfant interactions are often described as more physically stimulating and arousing, in comparison with more smoothly adapted episodes of reciprocity of gaze, vocalizations and positive affect during maternal interactions (Yogman, 1977; Belsky, 1979; Power, 1985). Despite these differences, some similarities in the effects of depression are seen. Depressed fathers, like depressed mothers, tend to be withdrawn and demonstrate negative affect in their behavioural interaction with their infants (Zaslow et al. 1985; Edhborg et al. 2005; Davis et al. 2011). It is as yet unknown whether any such similarities (or differences) map onto parents' verbal interactions with their infants.

The first key aspect of parental speech, cognitive bias, has two components, the attentional focus of a parent's speech register, and the affective quality (the positive or negative affect of the speech). General evidence suggests that depressed adults tend to demonstrate negatively biased self-perceptions, and increased attentiveness to and recall of negative stimuli (for a review of this literature, see Mathews \& Macleod, 2005). In depressed parents, these negative automatic thoughts extend beyond a biased judgement of the self, to manifest in both behavioural (Alloy et al. 2001) and verbal features of parenting (Kaminer et al. 2007). Negative automatic thoughts are evidenced by high levels of criticism, rejection and control (Alloy et al. 2001). Furthermore, depressed parents tend to express increased anger and decreased positive affect, empathic responses and praise during play with their child (Cohn \& Tronick, 1989; Cohn et al. 1990; Murray et al. 1993; Field, 1995). Depressed individuals also have an increased tendency to focus on the self rather than on the external environment (Mor \& Winquist, 2002).

Three studies from the maternal literature (Murray et al. 1993, 1996b; Herrera et al. 2004; Kaminer et al. 2007) have examined cognitive biases in the context of maternal psychopathology. Murray et al. (1993) compared the speech of depressed and well mothers with their 2-month-old infants and found that depressed mothers expressed more negativity compared with controls or with mothers experiencing a depressive episode only prior to delivery. Furthermore, in reporting the development of depressive cognitions in 5-year-olds, Murray et al. (2001) have also shown negativity in maternal speech to partially mediate the association with maternal depression. Kaminer et al. (2007), in contrast, did not find a direct effect of maternal depression on speech, but did find that increased maternal self-criticism was associated with an increased focus on maternal experience and less on infant experience. Herrera et al. (2004) analysed maternal speech at 6 and 10 months postpartum. At 6 months, depressed mothers focused less on affective (i.e. internal states and feelings) and informative (i.e. activity and external environment) features in their speech than non-depressed mothers, and at 10 months depressed mothers were more negative with their infants. To our knowledge the impact of depression on cognitive biases in the speech patterns of fathers has not been examined previously. Findings from a study analysing paternal speech in the context of paternal depression indicates that decreased vocal pitch in the speech of depressed fathers is less effective in promoting voice-face recognition in their infants (Kaplan et al. 2007).

The second key aspect of parental speech examined in this study is mentalization. Like attribution of agency (Murray et al. 1993), both RF and MMM consider 'the capacity to ascribe thoughts, feelings, ideas, and intentions to ourselves as well as to others, and to employ this capacity in order to anticipate and influence our own and other's behaviour' (Sharp \& Fonagy, 2008, p. 738). However, the measures used to index mentalization may vary. Whilst MMM is observed in the context of real parent-child interactions, $\mathrm{RF}$ is measured through the parents' representations of their attachment relationships, in the context of a clinical interview. Most of the existing evidence on MMM (among low-risk community samples) exists in the context of mother-child interactions, indicating that caregiver mentalization in the first year of life predicts infant-caregiver attachment security (Arnott \& Meins, 2007), and children's theory of mind 
abilities at the age of 4 years (Meins et al. 2002). Moreover, problems in parental mentalization have been linked to adverse child outcomes (Sharp \& Fonagy, 2008).

Limited research on mentalizing capacity in paternal speech has been examined in relation to infant attachment (Lundy, 2003; Arnott \& Meins, 2007), children's social and cognitive development (LaBounty et al. 2008) and in understanding mental states about fathering during pregnancy (Lis et al. 2004), but never in relation to paternal depression. There are limited studies of mentalizing in mothers. Murray et al. (1993) have reported that depressed mothers are less likely to acknowledge infant intentions and agency, compared with non-depressed mothers. Similarly, Herrera et al. (2004) found that mothers with depression made fewer references to their infants' emotional and cognitive experience in their speech and a recent study of in-patients found that depressed mothers, compared with healthy controls, were marginally less likely to comment on their infants' mental state (Pawlby et al. 2010).

Our objective in the present study was to examine the speech of depressed and non-depressed fathers during father-infant interactions at 3 months. We examined the impact of fathers' depression on the attentional focus and affective quality of their speech, and in their use of mentalizing comments. We hypothesized that, compared with non-depressed fathers, fathers with depression would demonstrate: (i) more speech focused on paternal experience (father-focused) and less on the infant's experience (infant-focused); (ii) increased negativity, in terms of more negative and critical comments about the infant (infant-focused negativity) and about the self (father-focused negativity); and (iii) fewer comments relating to the infant's mental state, i.e. feelings, beliefs, intentions and desires (mentalizing comments)

\section{Method}

\section{Study design}

This study utilized an individually matched design. A sample of 38 fathers (19 with current major depressive disorder and 19 without depression) were matched on age and education. Samples were matched and constructed using the nearest available matching method (Rosenbaum \& Rubin, 1985). Controls were selected from a larger sample of fathers, and individually matched to the closest year for age and by educational grouping depending on the highest level of qualification [General Certificate of General Education (GCSE)/A level/degree/postgraduate].

\section{Participants}

Participants were recruited from postnatal wards in Oxfordshire and Buckinghamshire, UK, as part of a longitudinal study. Details of the recruitment to the wider study are available elsewhere (Edmondson et al. 2010; Ramchandani et al. 2011). All fathers recruited into the study were aged 18 years or older, spoke English, were married or in a stable relationship and were residing with their infant. Infants were of gestational age $>36$ weeks, birth weight $\geqslant 2 \mathrm{~kg}$ and had no major congenital anomalies.

Using the 'matched pair method' the two study groups were selected, comprising fathers diagnosed as experiencing a current episode of major depression $(n=19)$ when their child was aged 3 months, and a group of non-depressed fathers, with no current or past diagnosis of depression or elevated symptoms on a screening questionnaire, the Edinburgh Postnatal Depression Scale (Cox et al. 1987). These 38 fathers had a mean age of 35.89 (s.D. $=5.42$ ) years, were $94.7 \%$ white and all were married or cohabiting. In terms of highest level of educational attainment, $10.5 \%$ had GCSEs, and $21.1 \%$ had post-graduate qualifications; $92.1 \%$ of the fathers were in full-time employment. For all but two fathers, English was their first language. Of the infants, $18(47.4 \%)$ were first born and $14(36.8 \%)$ second born. There were no differences between the diagnostic groups on infant (gender and birth order) and paternal demographic characteristics (marital status, ethnicity and employment status) (Table 1).

\section{Procedure}

Data for this study were collected 3 months post-birth. All assessments were conducted in the families' homes. The assessment of father-infant interactions used a standard assessment protocol (Murray et al. 1996a). Fathers were seated opposite their infant, who was placed in an infant seat, allowing face-to-face engagement at eye level. The infant seat was placed alongside a front-surfaced mirror on a table and a video camera was positioned in such a way so as to capture a front view of the infant's face and torso, and a reflection of the father's face and upper torso. Fathers were instructed to play with and talk to their infants as they would normally do without the use of any toys for $3 \mathrm{~min}$. Following the observational assessment, all fathers were interviewed using a structured psychiatric interview.

Paternal speech was transcribed verbatim from videotapes of the interaction. An utterance was defined as a group of words bounded by silence, a short pause or intonation to signal a question mark or period at the end of the sentence or thought. Single words, 
Table 1. Comparison of paternal and infant demographic characteristics by paternal diagnostic status

\begin{tabular}{|c|c|c|c|}
\hline Sample characteristic & $\begin{array}{l}\text { Currently depressed } \\
(n=19)\end{array}$ & $\begin{array}{l}\text { Non-depressed } \\
(n=19)\end{array}$ & Statistics \\
\hline Mean paternal age, years (S.D.) & $36.26(5.94)$ & $34.11(8.93)$ & $t_{36}=0.877, p=0.387$ \\
\hline \multicolumn{4}{|l|}{ Paternal education level, $n(\%)$} \\
\hline No qualification & $5(26.3)$ & $6(31.6)$ & \multirow[t]{4}{*}{$\chi^{2}=0.334, p=0.841$} \\
\hline Diploma & $4(21.1)$ & $2(10.5)$ & \\
\hline College degree & $6(31.6)$ & $7(36.8)$ & \\
\hline Postgraduate & $4(2.1)$ & $4(21.1)$ & \\
\hline \multicolumn{4}{|l|}{ Marital status, $n(\%)$} \\
\hline Single & - & - & \multirow[t]{2}{*}{-} \\
\hline Married & $19(100)$ & $19(100)$ & \\
\hline \multicolumn{4}{|l|}{ Ethnicity, $n(\%)$} \\
\hline White & $18(94.7)$ & $17(94.4)$ & \multirow[t]{2}{*}{$\chi^{2}=0.002, p=0.969$} \\
\hline Non-white & $1(5.3)$ & $1(5.6)$ & \\
\hline \multicolumn{4}{|l|}{ Infant gender, $n(\%)$} \\
\hline Female & $12(63.2)$ & $12(63.2)$ & \multirow[t]{2}{*}{$\chi^{2}=0.00, p=1.00$} \\
\hline Male & $7(36.8)$ & $7(36.8)$ & \\
\hline \multicolumn{4}{|l|}{ Birth order, $n(\%)$} \\
\hline First & $8(42.1)$ & $9(47.4)$ & \multirow[t]{4}{*}{$\chi^{2}=3.13, p=0.373$} \\
\hline Second & $8(42.1)$ & $7(36.8)$ & \\
\hline Third & $1(5.3)$ & $3(15.8)$ & \\
\hline Fourth & $2(10.5)$ & $0(0)$ & \\
\hline
\end{tabular}

S.D., Standard deviation.

sentence fragments, non-verbal sounds and songs were each counted as an utterance. In addition to transcribing paternal utterances, the context in which they were made was also indicated on the script. Where sound was not clear $(n=3)$, reliability was established by asking a different member of the research team to independently transcribe the section. Reference to video-clips was made in order to clarify affective tone, infant behaviour/response, and ambiguity in context of utterances concerning infant attention and gaze.

\section{Measures}

\section{Structured psychiatric interview}

The Structured Clinical Interview for DSM-IV Axis I Disorders (SCID; First et al. 2002) was used for diagnosing major depressive disorder. The SCID has been found to have high reliability (Zanarini et al. 2000) and validity (Basco et al. 2000). All interviews were conducted by trained graduate psychologists or psychiatrists.

\section{Paternal speech}

Paternal speech was examined using The PaternalCognitive Attributions and Mentalizing Scale (manual available from the authors upon request). This scale was adapted and developed from two related systems previously developed for examining maternal speech during mother-infant interactions. The primary source was the previous work of Murray and colleagues (Murray \& Trevarthen, 1986; Murray et al. 1993), but we also incorporated specific mentalization categories from the construct of 'mind-mindedness' (Meins et al. 2001). The scales consisted of three main groups of variables of interest: (I) the overall attentional focus of speech; (II) the negative or positive focus of speech; and (III) mentalizing comments in speech.

\section{Overall attentional focus of speech}

The overall attentional focus of speech comprised four dimensions: (1) infant-focused speech; (2) fatherfocused speech; (3) experiential-focused speech; and (4) other-focused speech.

Infant-focused speech included comments directed to, or about, the infant. This dimension reflected the father's overall ability to understand and interpret his infant's mental state (e.g. 'you like this seat'), focus of attention (e.g. 'are you looking at the lights?') and motor movements (e.g. 'are you trying to touch Daddy?'). Also included were comments on the 
infant's physical attributes, or general description (e.g. 'beautiful eyes you have', 'you have pink socks') and attention orienting and maintaining speech (e.g. the use of greetings and songs).

Father-focused speech predominantly captured comments made by the father about himself reflecting an explicit focus on his own thoughts, feelings and experiences (e.g. 'I'm not able to make you smile', 'Daddy's not as good as Mummy'). Also included were comments about the infant reflecting an implicit focus on the father's desire for control, in the form of strong commands and instructions directed towards correcting infant behaviour. Comments such as 'don't frown at me, smile like you smile at Mummy', suggest the infant perform in a way consistent with his/her father's request. This perspective was taken from the previous work conducted by Murray and colleagues with mothers' speech (Murray et al. 1993; p. 1087).

Experiential-focused speech captured comments on the context of interaction (e.g. 'this car seat is like yours') and those indicating implicit signs of discomfort/situation consciousness (e.g. 'it's difficult without toys'). Also coded were comments specific to the set-up of the interaction (e.g. presence of the camera or the infant seat).

Other-focused speech included comments that were not directly related to the current play context and removed in time and place (e.g. 'I wonder what Mummy is doing', 'you had a long sleep').

\section{Negative versus positive focus of speech}

Each utterance was coded for the degree to which statements were negative, positive or neutral in order to establish overall affective focus across the 3-min speech sample. Additionally, the negative levels of father-focused and infant-focused speech were also examined. The two ratings are independent.

\section{Mentalizing comments in speech}

Mentalizing comments included internal and external state comments. Internal state comments included: sensitivity to mental states, i.e. cognitive state comments (e.g. 'you like this seat'); feeling states, i.e. emotional state comments (e.g. 'happy baby'); and somatic functioning, i.e. physiological state comments (e.g. 'are you tired?'). External state comments reflected the father's capacity to identify the infant's attention and its focus (e.g. 'are you looking at the lights?'); motor movements (e.g. 'are you trying to touch Daddy?'); and vocal expressions (e.g. response to vocalizations and mouthings: 'you're trying to talk to me; do you want to tell me something?'). Paternal response to the infant's emotions, behaviour and vocalization were coded to represent the father's acknowledgement and interpretation of infant intensions. This is in line with prior research on MMM (Meins \& Fernyhough, 1999). For example, in the process of interpreting infant vocalizations, the father recognizes that the infant is actually intending to convey some message.

\section{Coding the paternal speech}

Videotapes were coded by two researchers blind to paternal depression status. Individual variable scores were calculated by summing total number of utterances. Analyses were conducted using proportions of the total number of utterances.

Inter-rater reliability was examined using the intraclass correlation coefficient (ICC) on a randomly selected $25 \%$ of the speech samples. ICC is an appropriate statistical method for studying agreement between sets of continuous data in small samples $(n<15)$. ICC coefficients $>0.75$ are usually accepted as evidence of good agreement (Maynard et al. 2003). Inter-rater reliability on the four dimensions of the overall focus of speech was as follows: infant-focused speech [ICC $=0.98$, 95\% confidence interval (CI) $0.95-0.99, p<0.001$ ] father-focused speech (ICC $=0.94,95 \%$ CI $0.78-0.98$, $p<0.001$ ); experiential-focused speech (ICC $=0.60$, 95\% CI 0.59-0.90, $p=0.091)$; and other-focused speech (ICC $=0.89,95 \%$ CI $0.63-0.97, p<0.001)$. Reliability on the affective focus of speech was: positive comments (ICC $=0.83,95 \%$ CI $0.78-0.89)$; negative comments (ICC $=0.89$, 95\% CI 0.75-0.95); and neutral comments (ICC $=0.84,95 \%$ CI $0.71-0.92$ ).

\section{Infant behaviours}

Observational measures of infant behaviour were coded using The Global Rating Scales for MotherInfant Interaction (GRS; Murray et al. 1996a). The GRS comprise individual infant behaviours rated on fivepoint scales ranging from 1 (e.g. distressed) to 5 (e.g. happy). The scales were subsequently clustered into the following dimensions as per standard use in previous research with a possible range from 1 to 5 . 'Infant fretfulness' during mother-infant interactions comprised two infant behaviour scales from the GRS: (i) happy-distressed and (ii) non-fretful-fretful.

We also coded for the following infant dimensions from father-infant interactions: (A) 'infant fretfulness'; (B) 'infant attentiveness and communication'; and (C) 'infant liveliness', using the same GRS as for mother-infant interaction.

The inter-rater reliability was calculated as ICCs for each scale. For scales from mother-infant interactions, happy-distressed ICC was 0.72, and for non-fretfulfretful ICC was 0.82. For scales from father-infant interactions, ICCs were: happy-distressed, 0.79; 
non-fretful-fretful, 0.84; attentive-avoidant, 0.85; active communication-no active communication, 0.86 ; positive vocalizations-no positive vocalizations, 0.80 ; lively-inert, 0.79; engaged-self-absorbed, 0.81 .

\section{Analytic strategy}

First, infant (gender and birth order) and paternal (age, marital status, educational attainment and ethnicity) characteristics were examined in relation to paternal depressive status and paternal speech. Second, we examined how infant fretfulness related to the main independent and dependent study variables. Non-parametric statistics were used for the above analyses, i.e. the Mann-Whitney test and Spearman correlation. Third, the main comparisons of depressed and non-depressed fathers' speech were undertaken, comparing: (a) the overall focus of paternal speech; $(b)$ negative versus positive comments; and (c) mentalizing comments. Non-parametric Wilcoxon signed ranks tests for matched data were used. Non-parametric statistics were used as the sample was small, and there were several nonnormal distributions. Finally, group differences were re-examined, controlling for any effect of infant fretfulness, using multiple linear regression analysis. Fretfulness was included a priori, as it has been considered as an important covariate in previous studies, and may have an impact particularly on the way in which a father views and talks about his infant.

\section{Results}

Infant and paternal demographic characteristics examined in relation to paternal depression and speech

Infant and paternal demographic variables did not differ by paternal diagnostic status (see Table 1).

Infant gender was not associated with any of the paternal speech variables. There was some evidence that infant birth order was associated with paternal use of mentalizing comments $(Z=-1.71, p=0.086)$; fathers of first-born infants used more mentalizing comments than fathers with other children.

Paternal age was associated with the proportion of mentalizing comments $(\rho=-0.35, p=0.030)$ and with infant-focused comments $(\rho=-0.32, p=0.054)$, suggesting that older fathers used fewer mentalizing and infant-focused comments. Paternal education was marginally related to the proportion of infant-focused negative comments $\left(\chi^{2}=7.01, p=0.072\right)$; fathers with no qualifications used a greater proportion of infantfocused negative comments (mean $=0.214$ ) compared with those who had degree-level qualifications (mean $=0.061)$. Paternal speech characteristics were not associated with paternal ethnicity or with marital status.

\section{Infant behaviours studied in relation to paternal depressive status and speech}

Infant fretfulness was not associated with paternal depressive status or with the main speech variables. Similarly, paternal depression was not associated with any of the infant behaviours from father-infant interactions.

\section{Differences in the speech of depressed and non-depressed fathers}

Preliminary analysis suggested that the mean number of utterances over the 3-min interaction was less for depressed fathers $($ mean $=53.42$, s.D. $=16.05)$ compared with non-depressed fathers (mean $=61.53$, S.D. $=15.83)(Z=-1.65, p=0.098)$. In order to control for any possible effects of depression on overall amount of speech, scores for each category were calculated as a proportion of the total number of utterances.

\section{The focus of fathers' speech}

The speech of depressed fathers compared with nondepressed fathers was more focused on their own experience $(Z=-2.1, p=0.014)$ and less on their infants' experience $(Z=-2.37, p=0.008)$. There were no group differences on experiential-focused and other-focused speech scales (see Table 2).

\section{Negativity in paternal speech}

As shown in Table 3, paternal depression was associated with an increased proportion of overall negative comments $(Z=-2.09, p=0.018)$, including both infant-focused negativity $(Z=-2.01, p=0.002)$ and father-focused negativity $(Z=-1.08, p=0.032)$. In keeping with this, depressed fathers also made more critical comments about their infants $(Z=-1.99$, $p=0.031$ ).

\section{Mentalizing comments}

There were no differences between depressed and non-depressed fathers in the overall mean proportion of mentalizing comments made (see Table 4). However, depressed fathers made fewer mentalizing comments in relation to the infants' physiological state compared with non-depressed fathers $(Z=-2.13$, $p=0.016)$. There were no differences in the mean proportion of external state comments between the study groups. 
Table 2. Proportion of comments on the overall focus of speech by paternal diagnostic group ${ }^{\text {a }}$

\begin{tabular}{lllll}
\hline Focus of speech & $\begin{array}{l}\text { Currently depressed } \\
(n=19)\end{array}$ & $\begin{array}{l}\text { Non-depressed } \\
(n=19)\end{array}$ & $Z^{\mathrm{b}}$ & $P$ \\
\hline Infant focused & $0.60(0.15)$ & $0.72(0.12)$ & -2.37 & 0.008 \\
Father focused & $0.24(0.17)$ & $0.14(0.11)$ & -2.17 & 0.014 \\
Experiential focused & $0.02(0.02)$ & $0.02(0.05)$ & -0.18 & 0.441 \\
Other focused & $0.04(0.07)$ & $0.04(0.06)$ & -0.05 & 0.500 \\
\hline
\end{tabular}

Data are given as mean (standard deviation)

${ }^{a}$ To facilitate interpretation of the tabulated results on group differences we report means and standard deviations rather than medians and an interquartile range. Utterances denoting questions and statements that could not be coded under the above four dimensions were excluded from the analysis and hence the mean proportions do not sum up to 1 .

${ }^{\mathrm{b}}$ Wilcoxon signed ranks.

Table 3. Affective focus in the speech of depressed and non-depressed fathers

\begin{tabular}{|c|c|c|c|c|}
\hline & $\begin{array}{l}\text { Currently depressed } \\
(n=19)\end{array}$ & $\begin{array}{l}\text { Non-depressed } \\
(n=19)\end{array}$ & $Z^{\mathrm{a}}$ & $p$ \\
\hline \multicolumn{5}{|l|}{ Overall affective focus } \\
\hline Positive & $0.09(0.10)$ & $0.11(0.10)$ & -0.07 & 0.482 \\
\hline Negative & $0.19(0.16)$ & $0.11(0.13)$ & -2.09 & 0.018 \\
\hline Neutral & $0.68(0.14)$ & $0.77(0.13)$ & -1.89 & 0.030 \\
\hline Infant-focused negativity ${ }^{\mathrm{b}}$ & $0.17(0.15)$ & $0.09(0.10)$ & -2.01 & 0.002 \\
\hline 1. Negative mentalizing & $0.08(0.09)$ & $0.06(0.08)$ & -1.41 & 0.084 \\
\hline 2. Negative comments & $0.02(0.06)$ & $0.00(0.00)$ & -1.99 & 0.031 \\
\hline 3. Corrections & $0.05(0.07)$ & $0.03(0.04)$ & -1.35 & 0.097 \\
\hline 4. Directive speech & $0.01(0.02)$ & $0.00(0.01)$ & -2.03 & 0.023 \\
\hline Father-focused negativity ${ }^{c}$ & $0.02(0.04)$ & $0.00(0.01)$ & -1.87 & 0.032 \\
\hline 1. Negative self-statements & $0.003(0.01)$ & $0.001(0.00)$ & -0.813 & 0.416 \\
\hline 2. Helplessness & $0.01(0.03)$ & $0.00(0.01)$ & -1.36 & 0.173 \\
\hline 3. Implicit discomfort & $0.01(0.03)$ & $0.00(0.00)$ & -1.60 & 0.109 \\
\hline
\end{tabular}

Data are given as mean (standard deviation).

a Wilcoxon signed ranks.

${ }^{\mathrm{b}}$ Overall total for the negative level of infant-focused comments.

${ }^{c}$ Overall total for the negative level of father-focused comments.

\section{Controlling for infant fretfulness}

In order to account for the potential for more fretful infants to elicit more negative speech in fathers, we then controlled for the effects of infant fretfulness. Paternal depression continued to predict infantdirected negativity, albeit more weakly, even when controlling for infant fretfulness $(\beta=-0.29, p=0.064$; compared with $\beta=-0.33, p=0.046$ prior to controlling for fretfulness). The overall model was significant $\left(F_{2,35}=4.59, p<0.05\right)$ and explained $18.6 \%$ of the variance in infant-directed negativity.

\section{Discussion}

This investigation examined cognitive biases (the attentional focus and affective quality) and the degree of mentalizing in the speech of depressed and nondepressed fathers. Depression in fathers was associated with more speech focused on the paternal experience and less on the infants' experience. Depressed fathers were also more negative about themselves and their infants compared with nondepressed fathers. There were no reported differences in the use of overall mentalizing comments in the two groups.

Before considering these findings in more detail, a number of strengths and limitations of the study should be noted. First, this is the first study to examine the impact of depression on cognitive biases and mentalizing in paternal speech with young infants. Analysing speech as early as 3 months is important, as this is a critical phase of child development, where the infant may be particularly susceptible to 
Table 4. Proportion of mentalizing statements, by paternal diagnostic group

\begin{tabular}{lllll}
\hline Mentalizing subscales & $\begin{array}{l}\text { Currently depressed } \\
(n=19)\end{array}$ & $\begin{array}{l}\text { Non-depressed } \\
(n=19)\end{array}$ & $Z^{\mathrm{a}}$ & $p$ \\
\hline Overall mentalizing comments & $0.32(0.16)$ & $0.37(0.12)$ & -1.01 & 0.166 \\
$\quad$ Internal state comments & $0.16(0.097)$ & $0.16(0.11)$ & -0.16 & 0.445 \\
1. Cognitive & $0.06(0.06)$ & $0.06(0.06)$ & -2.40 & 0.416 \\
2. Emotional & $0.09(0.09)$ & $0.05(0.05)$ & -1.37 & 0.091 \\
3. Physiological state & $0.02(0.02)$ & $0.05(0.06)$ & -2.13 & 0.016 \\
External state comments & $0.17(0.11)$ & $0.21(0.11)$ & -0.97 & 0.176 \\
1. Gaze/attention & $0.05(0.05)$ & $0.04(0.05)$ & -0.45 & 0.335 \\
2. Motor movements & $0.02(0.03)$ & $0.03(0.04)$ & -0.31 & 0.396 \\
3. Vocalizations and mouthing & $0.10(0.08)$ & $0.15(0.12)$ & -0.98 & 0.173 \\
\hline
\end{tabular}

Data are given as mean (standard deviation).

${ }^{a}$ Wilcoxon signed ranks.

environmental influences such as parenting. Second, clinical interviews were used to diagnose depressive disorder, yielding a group with clinically significant depression. Third, paternal speech was rated by coders who were blind to paternal case status, and adequate reliability on the scales was achieved. Finally, an independent, observational rating of infant temperament was used to control for the effects of the infant's contribution to the interaction.

This study also has some limitations. First, the modest sample size warrants caution. A relatively large number of tests were conducted in this exploratory study, and so there is a possible risk of type I errors. However, differences in scores between the two groups were consistently in the expected direction. In addition, participants were mainly Caucasian, middleclass, slightly older fathers, and so the findings should be generalized beyond this demographic cautiously. Third, further validation of the speech scales on a new sample is required, and, until then, these findings should be considered preliminary.

\section{The focus of speech}

Previous studies have shown that depressed people typically engage in higher levels of self-focus than do non-depressed people (Smith \& Greenberg, 1981; Ingram, 1984; Pyszczynski et al. 1989). Our results reflect these findings and are consistent with findings from studies of parents of older children, characterizing depressed parents as 'self-absorbed, ruminative and preoccupied' (Gelfand \& Teti, 1990). Research with mothers also reports that mothers who experienced depression were more likely to focus on the self and less on the infants' experience (Murray et al. 1993).

Depressed individuals also experience judgemental biases in the form of attending selectively to negative information and recalling less positive and more negative events (Mor \& Winquist, 2002). Depressed fathers' speech in this study included self-focused negativity ('oh, oh Daddy hasn't lasted very long has he?') and helpless comments ('can't think of anything to do all of a sudden'). This finding is consistent with previous work that suggests that depressed individuals process and recall information negatively when it is relevant to them (Ingram, 1984). The negativity directed towards the self may be explained in part by the attributional model of Abramson et al. (1978). In the event of infant fretfulness and failure to promote positive emotionality in interactions, depressed fathers are likely to attribute their failure to 'internal, stable and global causes'. The 3-min interaction in which we examine speech is likely to generate some stress for the father, generating feelings of incompetence and negativity towards the self.

The results of this study, suggesting that depressed fathers' attributions about their infants are more negative, correspond to the speech patterns seen in depressed mothers (Murray et al. 1993; Zlochower \& Cohn, 1996), and general parenting in the context of depression. Although there is no previous work on these negative communications in depressed fathers with their infants, Jacob \& Johnson (2001) have found parallel findings in a study on marital communication. Here, sequential analyses of paternal remarks indicated that depressed men showed less positivity following positive remarks made by a partner. This pattern of 'positivity suppression' increased with depression severity.

\section{Mentalizing comments in speech}

The hypothesis that depressed fathers would communicate fewer mentalizing comments in their speech 
was not confirmed. It is possible that the infants' limited capacity for social-cognitive communication at 3 months may explain why overall differences in mentalizing comments were not found, and it is possible that the context of the assessment may have been influential; mental state talk is more likely during some type of activities and not others. As fathers tend to engage in more physical and arousing play, the face-to face car seat context may not facilitate this type of communication. It is of note that our findings on mentalization contrast with studies of depressed mothers and their infants (Murray et al. 1993), and it is possible that fathers may not be as familiar with their infants as mothers at this young age, and so are less able to reflect on their infants' mental state, or they may do so in an idiosyncratic way.

\section{Conclusions}

This exploratory study is the first to report on cognitive biases and mentalizing in the speech of depressed and non-depressed fathers. Our data allude to a possible pathway between paternal psychopathology and the development of cognitive vulnerability for offspring depression. Infants of depressed fathers exposed to a negative cognitive style of communication early in life may be adversely affected and these patterns of communication may remain part of the child's environment throughout development. Identifying the origins of cognitive vulnerability is a promising line of inquiry that could inform possibilities for preventive intervention.

\section{Acknowledgements}

The Oxford Fathers Project was supported by a Wellcome Trust clinical research fellowship to P.G.R. (no. 078434). The work of V.S. was funded by a Medical Research Council studentship. We gratefully acknowledge the contributions of Olivia Edmondson, Jane Iles, Lamprini Psychogiou, Haido Vlachos, Elena Netsi, Annemarie Lodder and fathers and their families for their participation.

\section{Declaration of Interest}

None.

\section{References}

Abkarian GG, Dworkin JP, Abkarian AK (2003). Fathers' speech to their children: perfect pitch or tin ear? Fathering 1, 27-50.
Abramson LY, Seligman MEP, Teasdale JD (1978). Learned helplessness in humans: critique and reformulation. Journal of Abnormal Psychology 87, 49-74.

Alloy L, Abramson L, Tashman L, Berrebbi D, Hogan M, Whitehouse W, Al E (2001). Developmental origins of cognitive vulnerability to depression: parenting, cognitive, and inferential feedback styles of the parents of individuals at high and low cognitive risk for depression. Cognitive Therapy and Research 25, 397-423.

Arnott B, Meins E (2007). Links among antenatal attachment representations, post-natal mindmindedness, and infant attachment security: a preliminary study of mothers and fathers. Bulletin of the Menninger Clinic 71, 132-149.

Basco MR, Bostic JQ, Davies D, Rush J, Witte B, Hendrickse W, Barnett V (2000). Methods to improve diagnostic accuracy in a community mental health setting. American Journal of Psychiatry 157, 1599-1609.

Beck AT (1976). Cognitive Therapy and the Emotional Disorders. International Universities Press: New York.

Belsky J (1979). Mother-father-infant interaction: a naturalistic observational study. Developmental Psychology 15, 601-607.

Cohn JF, Campbell SB, Matias R, Hopkins J (1990). Face-to-face interactions of postpartum depressed and nondepressed mother-infant pairs at two months. Developmental Psychology 26, 15-23.

Cohn JF, Tronick E (1989). Specificity of infants' response to mothers' affective behavior. Journal of the American Academy of Child and Adolescent Psychiatry 28, 242-248.

Cox JL, Holden JM, Sagovsky R (1987). Detection of postnatal depression: development of the 10-item Edinburgh Postnatal Depression Scale. British Journal of Psychiatry 150, 782-786.

Davis RN, Davis MM, Freed GL, Clark SJ (2011). Fathers' depression related to positive and negative parenting behaviours with 1-year old children. Pediatrics 127, 612-618.

Edhborg M, Matthiesen AS, Lundh W, Widstrom AM (2005). Some early indicators for depressive symptoms and bonding 2 months postpartum - a study of new mothers and fathers. Archives of Women's Mental Health $\mathbf{8}$, 221-231.

Edmondson OJH, Psychogiou L, Vlachos H, Netsi E, Ramchandani PG (2010). Depression in fathers in the postnatal period: assessment of the Edinburgh Postnatal Depression Scale as a screening measure. Journal of Affective Disorders 125, 362-368.

Fernald A, Taeschner T, Dunn J, Papousek M, De BoyssonBardies B, Fukui I (1989). A cross-language study of prosodic modifications in mothers' and fathers' speech to preverbal infants. Journal of Child Language 16, 477-501.

Field TM (1995). Psychologically depressed parents. In Handbook of Parenting: Vol. 4. Applied Practical Parenting (ed. M. H. Borstein), pp. 85-99. Lawrence Erlbaum Associates, Inc. : Mahwah, NJ.

First MB, Gibbon M, Spitzer RL, Williams JB (2002). Structured Clinical Interview for DSM-IV-TR Axis I Disorders, Research Version, Non-Patient Edition (SCID-I/NP). Biometrics Research, New York State Psychiatric Institute: New York. 
Fonagy P, Target M (2005). Bridging the transmission gap: an end to an important mystery of attachment research? Attachment and Human Development 7, 333-343.

Gelfand D, Teti D (1990). The effects of maternal depression on children. Clinical Psychology Review 10, 329-353.

Herrera E, Reissland N, Shepherd J (2004). Maternal touch and maternal child-directed speech: effects of depressed mood in the postnatal period. Journal of Affective Disorders 81, 29-39.

Ingram RE (1984). Depression and internal versus external focus of attention. Cognitive Therapy and Research 8, 139-152.

Jacob T, Johnson SL (2001). Sequential interactions in the parent-child communications of depressed fathers and depressed mothers. Journal of Family Psychology 15, 38-52.

Kaminer T, Beebe B, Jaffe J, Kelly K, Marquette L (2007). Mother's dependent and self-critical depressive experience is related to speech content with infants. Journal of Early Childhood and Infant Psychology 3, 163-184.

Kane P, Garber J (2009). Parental depression and child externalizing and internalizing symptoms: unique effects of father's symptoms and perceived conflict as a mediator. Journal of Child and Family Studies 18, 465-472.

Kaplan PS, Sliter JK, Burgess AP (2007). Infant-directed speech produced by fathers with symptoms of depression: effects on infant associative learning in a conditionedattention paradigm. Infant Behavior and Development 30, 535-545.

LaBounty J, Wellman HM, Olson S, Lagattuta K, Liu D, Liu D (2008). Mothers' and fathers' use of internal state talk with their young children. Social Development 17, 757-775.

Lis A, Zennaro A, Mazzeschi C, Pinto M (2004). Parental styles in prospective fathers: a research carried out using a semistructured interview during pregnancy. Infant Mental Health Journal 25, 149-162.

Low SM, Stocker C (2005). Family functioning and children's adjustment: associations among parents' depressed mood, marital hostility, parent-child hostility, and children's adjustment. Journal of Family Psychology 19, 394-403.

Lundy BL (2003). Father- and mother-infant face-to-face interactions: differences in mind-related comments and infant attachment? Infant Behavior and Development 26, 200-212.

Mathews A, Macleod C (2005). Cognitive vulnerability to emotional disorders. Annual Review of Clinical Psychology 1, 167-195.

Maynard V, Bakheit AM, Oldham J, Freeman J (2003). Intrarater and inter-rater reliability of gait measurements with CODA mpx30 motion analysis system. Gait and Posture 17, 59-67.

Meins E, Fernyhough C (1999). Linguistic acquisitional style and mentalising development: the role of maternal mindmindedness. Cognitive Development 14, 363-380.

Meins E, Fernyhough C, Fradley E, Tuckey M (2001). Rethinking maternal sensitivity: Mothers' comments on infants' mental processes predict security of attachment at 12 months. Journal of Child Psychology and Psychiatry 42, 637-648.

Meins E, Fernyhough C, Wainwright R, Clark-Carter D, Das Gupta M, Fradley E, Tuckey M (2002). Maternal mind-mindedness and attachment security as predictors of theory of mind understanding. Child Development 73, 1715-1726.

Mor N, Winquist J (2002). Self-focused attention and negative affect: a meta-analysis. Psychological Bulletin 128, 638-662.

Murray L, Fiori-Cowley A, Hooper R, Cooper P (1996a). The impact of postnatal depression and associated adversity on early mother-infant interactions and later infant outcome. Child Development 67, 2572-2526.

Murray L, Hipwell A, Hooper R, Stein A, Cooper P (1996b). The cognitive development of 5-year-old children of postnatally depressed mothers. Journal of Child Psychology and Psychiatry and Allied Disciplines 37, 927-935.

Murray L, Kempton C, Woolgar M, Hooper R (1993). Depressed mothers' speech to their infants and its relation to infant gender and cognitive devlopment. Journal of Child Psychology and Psychiatry 34, 1083-1101.

Murray L, Trevarthen C (1986). The infant's role in motherinfant communications. Journal of Child Language 13, 15-29.

Murray L, Woolgar M, Cooper P, Hipwell A (2001). Cognitive vulnerability to depression in 5-year-old children of depressed mothers. Journal of Child Psychology and Psychiatry 42, 891-899.

Pancsofar N, Vernon-Feagans L (2006). Mother and father language input to young children: contributions to later language development. Journal of Applied Developmental Psychology 27, 571-587.

Papousek M, Papousek H, Haekel M (1987). Didactic, adjustments in fathers' and mothers' speech to their 3-month-old infants. Journal of Psycholinguistic Research 16, 491-516.

Paulson JF, Bazemore SD (2010). Prenatal and postpartum depression in fathers and its association with maternal depression. Journal of the American Medical Association 303, 1961-1969.

Paulson JF, Keefe HA, Leiferman JA (2009). Early parental depression and child language development. Journal of Child Psychology and Psychiatry and Allied Disciplines 50, 254-262.

Pawlby S, Fernyhough C, Meins E, Pariante CM, Seneviratne G, Bentall RP (2010). Mind-mindedness and maternal responsiveness in infant mother interactions in mothers with severe mental illness. Psychological Medicine 40, 1861-1869.

Power TG (1985). Mother- and father-infant play: a developmental analysis. Child Development 56, 1514-1524.

Pyszczynski T, Hamilton JC, Herring FH, Greenberg J (1989). Depression, self-focused attention, and the negative memory bias. Journal of Personality and Social Psychology 57, 351-357.

Ramchandani PG, Psychogiou L (2009). Paternal psychiatric disorders and children's psychosocial development. Lancet 374, 646-653.

Ramchandani PG, Psychogiou L, Vlachos H, Iles J, Sethna V, Netsi E, Lodder A (2011). Paternal depression: an examination of its links with father, child and family functioning in the postnatal period. Depression and Anxiety 28, 471-477.

Ramchandani PG, Stein A, O'Connor TG, Heron J, Murray L, Evans J (2008). Depression in men in the 
postnatal period and later child psychopathology: a population cohort study. Journal of the American Academy of Child and Adolescent Psychiatry 47, 390-398.

Rosenbaum PR, Rubin DB (1985). Constructing a control group using multivariate matched sampling methods that incorporate the propensity score. American Statistician 39, 33-38.

Sharp C, Fonagy P (2008). The parent's capacity to treat the child as a psychological agent: constructs, measures and implications for developmental psychopathology. Social Development 17, 737-754.

Smith TW, Greenberg J (1981). Depression and self-focused attention. Motivation and Emotion 5, 323-331.

Wilson S, Durbin CE (2010). Effects of paternal depression on fathers' parenting behaviors: a meta-analytic review. Clinical Psychology Review 30, 167-180.
Yogman MW (1977). The Goals and Structure of Face-to-Face Interaction Between Infants and Fathers. Society for Research in Child Development: New Orleans.

Zanarini MC, Skodol AE, Bender D, Dolan R, Sanislow C, Schaefer E, Morey LC, Grilo CM, Shea MT, Mcglashan TH, Gunderson JG (2000). The Collaborative Longitudinal Personality Disorders Study: reliability of Axis I and II diagnoses. Journal of Personality Disorders 14, 291-299.

Zaslow MJ, Pedersen FA, Cain RL, Suwalsky JT, Kramer EL (1985). Depressed mood in new fathers: associations with parent-infant interaction. Genetic, Social, and General Psychology Monographs 111, 135-150.

Zlochower AJ, Cohn JF (1996). Vocal timing in face to face interaction of clinically depressed and non-depressed mothers and their 4 month old infants. Infant Behavior and Development 19, 371-374. 